\title{
STABILITY OF IMPLICIT RESOLVENT DYNAMICAL SYSTEMS
}

\author{
Muhammad Aslam Noor, Khalida Inayat NoOR And ZulfiQAR Ali Memon
}

\begin{abstract}
In this paper, we propose and analyze implicit resolvent dynamical systems associated with mixed quasi variational inequalities by using the techniques of the resolvent operators. We prove that the globally asymptotic stability of these dynamical systems requires monotonicity of the operator. We also discuss some special cases, which can be obtained from our main results.
\end{abstract}

Mathematics subject classification (2000): 49J40, 90C33.

Key words and phrases: Mixed variational inequalities, implicit dynamical systems, resolvent equations, global convergence, stability.

\section{REFERENCES}

1] C. Baiocchi And A. CAPelo, Variational and Quasi Variational Inequalities, J. Wiley and Sons, New York, 1984.

[2] T. R. BIELECKI AND S. R. PLISKA, Risk sensitive asset management with transaction costs, Finance and Stochastics, 4 (2000), 1-33.

[3] R. W. Cottle, F. GiANNESSI AND J. L. Lions, Variational Inequalities and Complementarity Problems: Theory and Applications, J. Wiley and Sons, New York, 1980.

[4] J. CRANK, Free and Moving Boundary Problems, Clarendon Press, Oxford, U. K., 1984.

[5] J. Dong, D. Zhang AND A. NAGURNeY, A projected dynamical systems model of general financial equilibrium with stability analysis, Math. Computer Modelling, 24 (2) (1996), 35-44.

[6] P. DupuIS AND A. NAgURNEY, Dynamical systems and variational inequalities, Annals Opers. Research, 44 (1993), 19-42.

[7] T. L. Friesz, D. H. Bernstein, N. J. Mehta And S. Ganjliazadeh, Day-to-day dynamic network disequilibria and idealized traveler information systems, Operations Research, 42 (1994), 1120-1136.

[8] T. L. FRIESZ, D. H. BERNSTEIN AND R. STOUGH, Dynamic systems, variational inequalities and control theoretic models for predicting time-varying urban network flows, Trans. Science, 30 (1996), 14-31.

[9] F. GianNeSSI AND A. MAUGERI, Variational Inequalities and Network Equilibrium Problems, Plenum Press, New York, 1995.

[10] F. Giannessi, A. Magueri and P. M. Pardalos, Equilibrium Problems: Nonsmooth Optimization and Variational inequality Models, Kluwer Academic Publishers, Dordrecht, Holland, 2001.

[11] R. Glowinski, J. L. LiOnS AND R. TREMOLIERES, Numerical Analysis of Variational inequalities, North-Holland, Amsterdam, Holland, 1981.

[12] N. KikUChi AND J. T. Oden, Contact Problems in Elasticity, SIAM Publishing Co., Philadelphia, 1988.

[13] D. Kinderlehrer AND G. StAMPACChIA, An Introduction to Variational Inequalities and Their Applications, SIAM Publishing Co., Philadelphia, 2000.

[14] A. Nagurney And D. Zhang, Projected Dynamical Systems and Variational Inequalities with Applications, Kluwer Academic Publishers, Dordrecht, Holland, 1995.

[15] M. Aslam Noor, On a class of variational inequalities, J. Math. Anal. Appl. 128 (1987), 135-155.

[16] M. Aslam Noor, Nonlinear variational inequalities in elastostatics, Int. J. Engg. Sci. 26 (1988), 1043-1053.

[17] M. Aslam Noor, Some recent advances in variational inequalities, Part I, basic concepts, New Zealand J. Math. 26 (1997), 53-80.

[18] M. Aslam Noor, Some recent advances in variational inequalities, Part II, other concepts, New Zealand J. Math. 26 (1997), 229-255. 
[19] M. Aslam Noor, Set-valued mixed quasi variational inequalities and implicit resolvent equations, Math. Computer Modelling, 29 (1999), 1-11.

[20] M. Aslam NoOR, Implicit dynamical systems for quasi variational inequalities, Appl. Math. Comput. 134 (2002), 69-81.

[21] M. AsLam NoOR, Resolvent dynamical systems for mixed variational inequalities, Korean J. Comput. Appl. Math. 9 (2002), 15-26.

[22] M. Aslam Noor, A Wiener-Hopf dynamical system for variational inequalities, New Zealand J. Math, 31 (2002), 173-182.

[23] M. Aslam NoOR, K. Inayat NoOR And Th. M. Rassias, Some aspects of variational inequalities, J. Comput. Appl. Math. 47 (1993), 285-312.

[24] G. STAMPaCCHIA, Formes bilineaires coercitives sur les ensembles convexes, C. R. Acad. Sci. Paris, 258 (1964), 4413-4416.

[25] Y. S. XIA AND J. WANG, A recurrent neural network for solving linear projection equations, Neural Network, 13 (2000), 337-350.

[26] Y. S. XIA AND J. WANG, On the stability of globally projected dynamical systems, J. Optim. Theory Appl. 106 (2000), 129-150.

[27] D. Zhang And A. NaguRney, On the stability of the projected dynamical systems, J. Optim. Theory and Appl. 85 (1995), 97-124. 